\title{
No Fact Check, Pharmaceutical Instituions from Reputed Pune University and Socially Situated and Socially Constituted Agency
}

\author{
Rahul Hajare* \\ Fellow Directorate of Pharmacy, New Delhi, India
}

Received: 阱 June 12, 2018; Published: 制June 19, 2018

*Corresponding author: Rahul Hajare, Fellow Directorate of Pharmacy, New Delhi, India

\begin{abstract}
The behavioral view of corporate governance has derived from the behavioral view of the firm, which arguably rests on more realistic assumptions than the economics rooted positive agency theory with regard to the heuristics of managerial action. In addition to the bounded rationality condition, the principle of satisfying and the assumption on routinisation in the decision-making process, the behavioral view treats organizations as complex social systems. They constitute venues of power battles among the coalitions of corporate actors realizing often conflicting goal agendas. It is therefore probably the most explicit about the existence of phenomena of power and politics in the corporate settings among all theories of the firm.
\end{abstract}

Keywords: PAT (Positive Agency Theory)

\section{Introduction}

Recently published work, suggest enriching the under socialized agency perspective with the predictions of the behavioural theory of the firm. They refer to this cross theoretical hybridization as the behavioural theory of corporate governance. Within that framework, they distinguish two main mechanisms that impact on behaviour and actions of actors involved in governance processes in corporations, i.e. the socially situated and socially constituted agency $[1,2]$. PAT, as an under socialized and actor centric theory, concentrates on examining patterns, according to which individuals voluntarily, however rationally, realize their own goal agendas. They are motivated by self-interest and differential personal risk preferences, as well as are subject to informational and incentive constraints. In effect, PAT governance mechanisms tend to be formal in nature. They take a form of either incentive for managers as agents or means of monitoring/controlling them. They are construed to provide safeguards against such actions of managers, who driven by their self-interest may be potentially deviating from the desired organizational and/or societal outcomes. This unfolds by aligning managerial interests with those of shareholders or disciplining managers as agents. Infuse the agency relationships with the social context. They emphasise that corporate leaders do not operate in the social vacuum. On the contrary, they act in the socially constructed and interpreted reality. In the methodological sense, they enrich the of the individual human action in corporate governance, as posited in PAT, with the social fabric of norms, values and beliefs, and point towards the socio-cognitive processes as actual frames, within which particular board members enact their decision-making processes $[3,4]$.

In other words, in this cross-theoretical framework and conceive the missing link between the macro-social explanations of well-functioning corporate governance practice, as offered by the economics-rooted PAT, and the micro-behaviour that is most likely to actually unfold in the boardroom reality. The term 'socially situated' is thought of in recognition of the fact that in any given situation individuals are enmeshed in a set of social relationships, networks, as well as institutions, which have influence on their perceived individual agency (e.g., a manager being accountable to non-executive directors directly, and to shareholders indirectly). Therefore, they represent crucial contingencies that ultimately shape the behaviour of individuals. The notion 'socially constituted', in turn, is conceived to capture a deeper kind of influence of the social context on the perception of the individual agency than it is the case with the socially situated agency. This concept emphasizes ways in which individuals' socialization into performance of their particular roles (e.g., as a manager, a Chairman, a non-executive director), as well as their cumulative personal experiences to 
date, determine what they regard as possible or realistic in a given situation. The perceived individual agency, shaped through these processes, ultimately precipitates in a specific socio-cognitive orientation that particular board members adopt in their socially constructed boardroom reality. There have emerged entire streams of empirical research, which, even if it does not fully explain the theoretical rationale of the suggested behavioural theory of corporate governance, explicitly examines the socio-cognitive processes and behavioural tactics that are likely to unfold in the boardroom reality. They act as contingencies that shape decisionmaking processes by particular board members. For example, predicts the likely board outcomes as a result of competition and collaboration between the executive and non-executive directors in the boardroom. Research pluralistic ignorance on boards. Scrutinize favour rendering, ingratiation tactics and norms of reciprocity. Analyze the processes of symbolic and impression management, together with organizational/ institutional decoupling [4,5]. Finally, look at the social distancing tactics as a means of disciplining and/ or demonstrating ostracism towards those minority coalitions, which step out of the line dictated by the dominant board fraction.

\section{Culturally determined agency}

The notions of social situatedness and constitution fall close to concept of habitus. He coined it in elaborating on his view of power as internalized constraints. His perspective is methodologically akin to the conceptualizations of power, who regarded it as a ubiquitous abstract and subtle force that is impacting on individuals in such a way, that they actually act as their own over-seers. They discipline themselves and the existing social relationships thus arise as the natural order. These arguments suggest that the individual agency as perceived by particular social actors is de facto socially constructed, whereby this process is hugely influenced by the position of a given actor in the existing structure of social relationships. In corporate governance of domestic firms, the socio-cognitive processes that shape board members' perception of their individual agency are described in the aforementioned contributions. However, such developments can also occur on Pharmaceutical Instituions' boards [6-8]. There is one characteristic, though, which makes corporate governance in Pharmaceutical Instituions distinctively different from corporate governance in their domestic counterparts.

This is the phenomenon of culture and cultural differences between nation states. It is also the distinctive feature of the entire international business research, and hence we have it as a separate field of study in management science. Without drilling deeply into intricacies of accountability chains on boards within the Pharmaceutical Institutions headquarters and within its foreign subsidiaries separately, I therefore propose the view of culturally determined agency. The notion is to capture the socio-cognitive processes that particular board members in a given foreign subsidiary and their counterparts in the Pharmaceutical Institutions headquarters are exposed to, being located at the interface of Luo's $(2005 a, 2005 b) 1^{\text {st }}$ - and $2^{\text {nd }}$-tier governance $[9,10]$. I suggest this view as a specific and distinctive feature of the corporate governance in Pharmaceutical Institutions. It incorporates cultural influences on the processes of social construction of the perceived individual agencies by particular board members at both governance levels and constitutes a significant portion of the overall variance of all types of impact factors on these processes $[11,12]$.

\section{Conclusion}

Other corporate governance mechanisms typically distinguished in the academic literature comprise:

a) Minority investors' protection rights.

b) Ownership concentration.

c) Incentive alignment (performance- related executive pay contingency).

d) Direct shareholders' control (e.g. voting at the annual general meeting (AGM)).

e) Managerial labour market (reputation effects).

f) Market for corporate control (takeover activity).

g) Product market competition.

\section{Controversies}

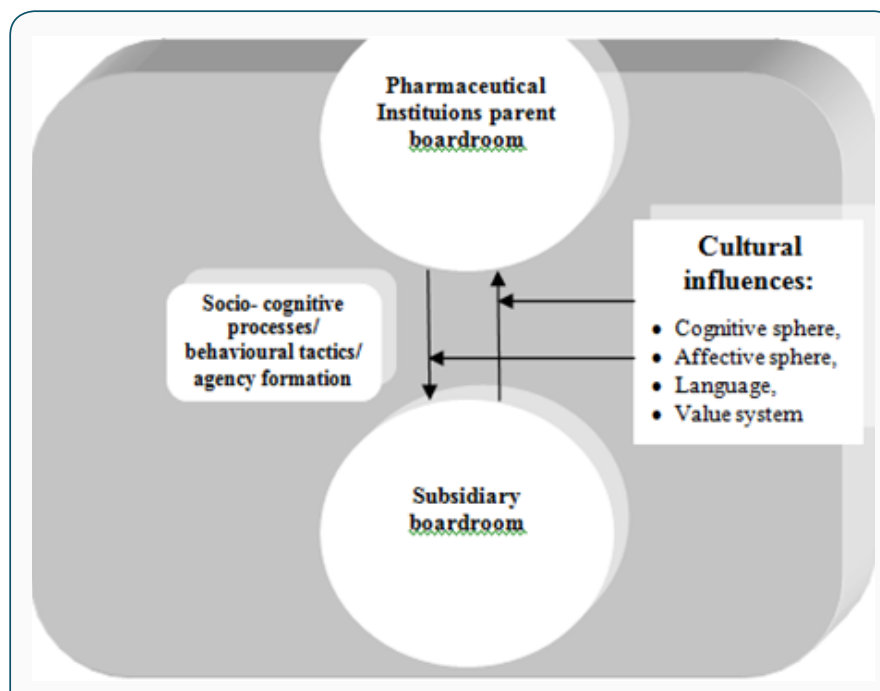

Figure 1: A model of culturally determined agency.

Pharmaceutical Instituions has putting less effort to national economic systems. Principal of the Institutions has not report to college in time. They have alcohol dependency and smoker addict [13-15]. Self-Report of such habit, Inconsistent alcohol use and Non-use are Poor Predictors of malpractice Prevalence among Pharmaceutical Instituions principal who have alcohol dependency with other Pharmaceutical Instituions Principal. Assessment of the population-level effectiveness of the Avahan bad habit -prevention programme in Pharmaceutical Instituions in India: a preplanned, causal-pathway-based modelling analysis has been under way. 
This reasoning is summarised in Figure 1 A model of culturally determined agency.

\section{Acknowledgment}

This study has been guided by under supervision and guidance of Retd. Director' National AIDS Research Institute India. I express my deep gratitude towards Respected Sir' for motivation and being great knowledge source for this research.

\section{References}

1. Rahul H (2018) Two Trajectories A Promise of Reform and Ashaaram Pattern. Degenerative Intellect Dev Disabil 1(3): 1-3.

2. Rahul H (2017) Understanding academic and educational problems fit for purpose in the contributing to attentional and learning difficulties in our children? Glob J Oto 11(5): 1-2.

3. Rahul H (2017) Live and let live: acceptance of learning disability of people living with co-educational pharmaceutical institute selffinanced and privately managed remote areas in India where stigma and discrimination persist. Current Opinions in Neurological Science 1(6): 311-313.

4. Hajare R (2017) Process from bio safety working style to accreditation trends driving self-financed private pharmacy institution in remote areas individuals in India. J Tradit Med Clin Natur 6: 230.

5. Rahul H (2018) Why No More Apes Evolving Into Humans. Res Med Eng Sci 4(4).

6. Rahul Hajare (2018) The biosafety against privately managed pharmacy institution in Savitribai Phule Pune University is not such a simple shot. Int J Nep \& Uro Dis 2(2): 6-7.
7. Rahul H (2018) Shocking Link of Rapid Rise in Pre-Cancer among the Healthy Adults in Pharmaceutical Institution Pune University India Living With Low Oxygen and Poor Sanitation Environment: Affordable Treatment Rate Three-Times Over. Glob J Add \& Rehab Med 5(5): 1-3.

8. Rahul H (2018) Regulation of Pharmacy Council of India and Assessment of Quality Life Among single Mother-By-Choice 'Residing in slums Linkage Pharmaceutical Institutions in Pune, India. Drug Des Int Prop Int J 1(3): 1-2.

9. Rahul Hajare (2018) There is no Cure for the Cancer of Stupidity. Organic \& Medicinal Chem IJ 5(1): 1-3.

10. Rahul Hajare (2018) An Attempt to Eradicate Alcohol Dependency from Adult Men in Service Privately Managed Pharmaceutical Institutions in India. Toxicology and Applied Pharmacology Insights 1(1): 1-2.

11. Rahul Hajare (2018) Depression-Level Effectiveness of the Curse Words in Young Adults in Pune University. J Clin Rev Case Rep 3(3): 1-4.

12. Rahul H (2018) Assessment of the Depression-Level Effectiveness of the Curse Words in Young Adults in Private Co-Educational Pharmaceutical Institutions in Pune University Pharmaceutical Institutions Living With Poor Sanitation, India: A Pre-planned, Causal Pathway-Based Analysis. J Gastrointest Disord Liver Func 4(1): 6- 10.

13. Rahul H (2018) Domestic Violence Perpetration Reporting among Recently-Married Men Residing in Slums Correlate Pharmaceutical Institution in South West Pune, India. Orthop \& Spo Med Op Acc J 1(3): $1-3$.

14. Rahul H (2017) A Defence of Unqualified Pharmaceutical Confidentiality. Glob J Add \& Rehab Med 4(3): 555636.

15. Rahul A Hajare (2018) 909090 Formulas and Symptoms of Adrenal Fatigue Syndrome (AFS) of Adult Men. Orthop \& Spo Med Op Acc J 1(3): $1-2$.

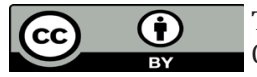

This work is licensed under Creative Commons Attribution 4.0 License

To Submit Your Article Click Here:

Submit Article

DOI: $10.32474 /$ OSMOAJ.2018.01.000115

$\begin{gathered}\text { Orthopedics and Sports Medicine } \\ \text { Open Access Journal }\end{gathered}$
Assets of Publishing with us
Global archiving of articles
- Immediate, unrestricted online access
- Rigorous Peer Review Process
- Authors Retain Copyrights
- Unique DoI for all articles

